\title{
ESTIMATION OF SUBSURFACE STRUCTURE OF LANDSLIDE AREA BASED ON MICROTREMOR OBSERVATION IN THE HOJOSHIMA, NAWASHIRO AND AMEDAKI AREA, TOTTORI, JAPAN
}

\author{
* Tatsuya Noguchi ${ }^{1}$, Isamu Nishimura ${ }^{1}$ and Takao Kagawa ${ }^{1}$ \\ ${ }^{1}$ Faculty of Engineering, Tottori University, Japan
}

*Corresponding Author, Received: 11 Nov. 2021, Revised: 01 Dec. 2021, Accepted: 18 Dec. 2021

\begin{abstract}
Investigating the subsurface structure of a landslide area is important for considering the hazards of slope disasters. In this study, microtremor exploration was conducted in three areas (Hojoshima, Nawashiro, and Amadaki) in Tottori Prefecture, which were judged to have landslide topography, and the subsurface structure was estimated as well. The target areas were based on a landslide topography distribution map published by the National Research Institute for Earth Science and Disaster Prevention. The results showed that the characteristics of tremors in the target area differed between the landslide moving mass, main scarp, and original subsurface areas. In addition, the velocity structure and thickness distribution of the landslide sedimentary layers in each area were estimated. In the Hojoshima area, where a building was damaged by the 2016 Central Tottori Earthquake, it was found that a landslide moving mass was deposited on the alluvium. In the Nawashiro area, landslides occurred in three areas, and it was found that the geology and sedimentary layer thickness differed in each area. In the Amedaki area, it was found that the soft sedimentary layer of the moving mass was thin and widely distributed. In the future, it will be necessary to evaluate landslide hazards based on subsurface structure information.
\end{abstract}

Keywords: Landslide area, Microtremor, Subsurface structure, Tottori Prefecture

\section{INTRODUCTION}

In recent years, earthquakes have caused largescale landslides. Strong ground motions caused widespread landslides during the 2009 West Sumatra Earthquake [1] and the 2018 Hokkaido
Eastern Iburi Earthquake [2]. Volcanic ash and weathered rock strata exist in the area, and landslides may have occurred repeatedly in the past. Because strong ground motions triggered widespread landslides in this area, it is important to investigate the subsurface structure in landslide

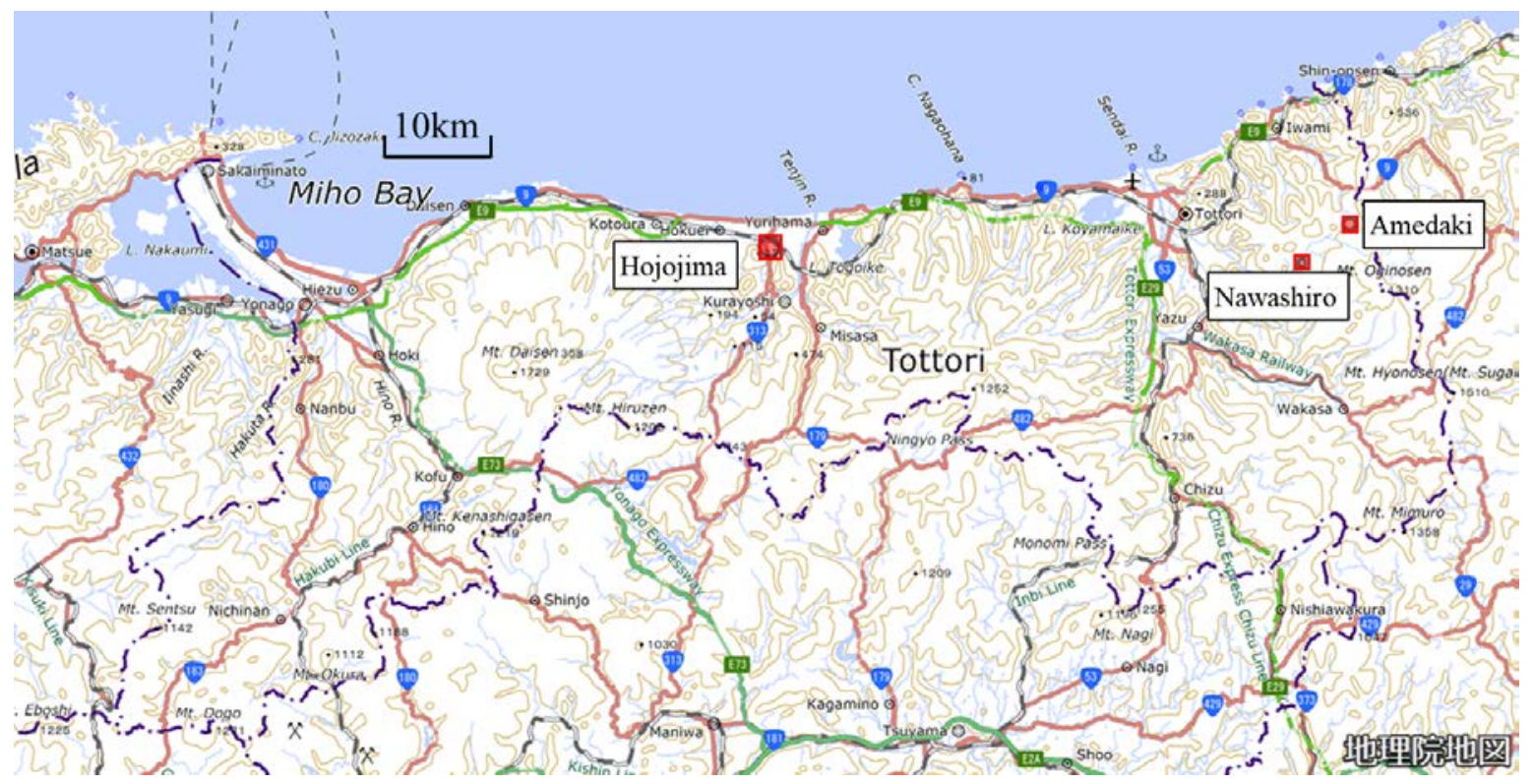

Fig. 1 Location of observation area (red frame) 


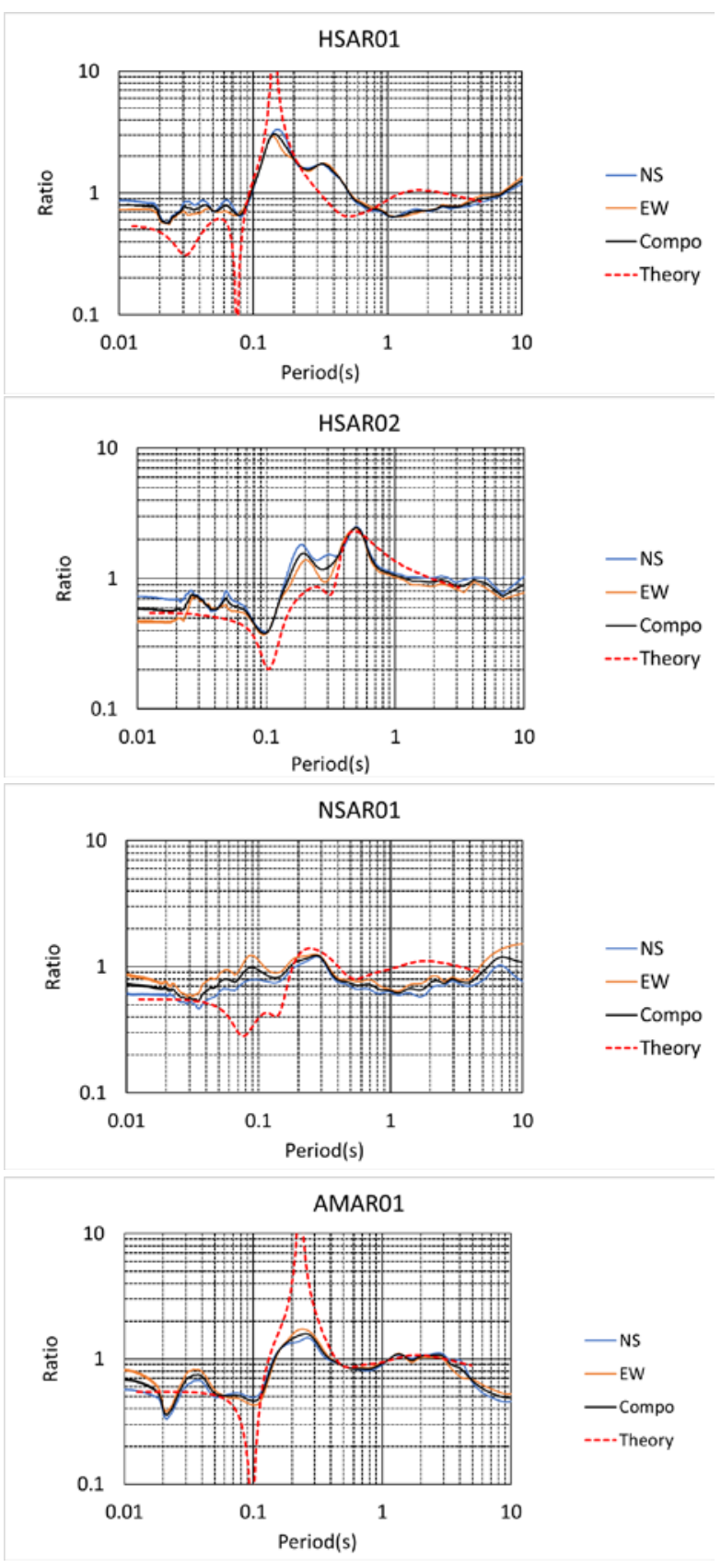

Fig. $2 \mathrm{H} / \mathrm{V}$ spectra of microtremors

areas and to consider slope hazards as well.

In this study, microtremor surveys were conducted in three areas (Hojoshima, Nawashiro, and Amedaki) in Tottori Prefecture, Japan (Fig.1), which were determined to have landslide terrain based on the landslide topography distribution map published by the National Research Institute for Earth Science and Disaster Prevention [3] [4]. Moreover, buildings were damaged in the Hojoshima area during the 2016 Central Tottori Earthquake [5]. The microtremor data were analyzed to understand the ground motion characteristics of the target areas. In addition, the layer thickness distribution of the landslide moving mass was determined by estimating the subsurface structure.

\section{OBSERVATION}

For microtremor observations, single-site observations of three components were conducted to determine the predominant period and amplification characteristics of the subsurface structure, and array observations were conducted to estimate the S-wave velocity structure. A threecomponent acceleration-type seismometer (JU410) was used for the observations, which can record microtremors with a period of $0.05-10 \mathrm{~s}$.

A total of 80 three-component single-site observations were conducted at Hojoshima (35 sites), Nawashiro (28 sites), Amedaki (17 sites), at intervals of $100 \mathrm{~m}$ to $200 \mathrm{~m}$. The sampling frequency for the measurement was $200 \mathrm{~Hz}$, and the observation time was 10 minutes for each site.

Array observations were carried out at four sites: two sites at Hojoshima (HSAR01, HSAR02), Nawashiro (NSAR01), and Amedaki (AMAR01). In Hojoshima, the subsurface structure is assumed to vary depending on the topography, therefore array observation points were set up at two locations with differing topographies. For the array observations, a point was placed at the center of a circle, and three points were placed at equal intervals on the perimeter of the circle. The radius of the circle (array radius) ranged from 1 to 20 meters. Each device was synchronized using a GPS clock. Because the power of the microtremors was expected to be small, three to four people jumped simultaneously approximately $5 \mathrm{~m}$ from the outer seismometer to provide an artificial seismic source and observe the waveform. The sampling frequency for the measurement was $200 \mathrm{~Hz}$, and the observation time was 10-15 minutes for each array.

\section{ANALYSIS}

For the analysis of the three-component singlesite observation data, at least 10 sections of $20.48 \mathrm{~s}$ periods without artificial noise were selected from the array observation records. The spectra were smoothed using a log window [6] with a coefficient of 20. The averaged Fourier spectra of the selected data for each component were used to create the horizontal components and subsequently calculate the horizontal-to-vertical spectral ratio $(\mathrm{H} / \mathrm{V}$ spectrum. The predominant periods were determined from the $\mathrm{H} / \mathrm{V}$ spectra obtained at each site. The $\mathrm{H} / \mathrm{V}$ spectra obtained from the seismometer at the center of the array observation are shown in Figure 2 (NS, north-south; EW, eastwest; Comp, composition, where the red dashed 


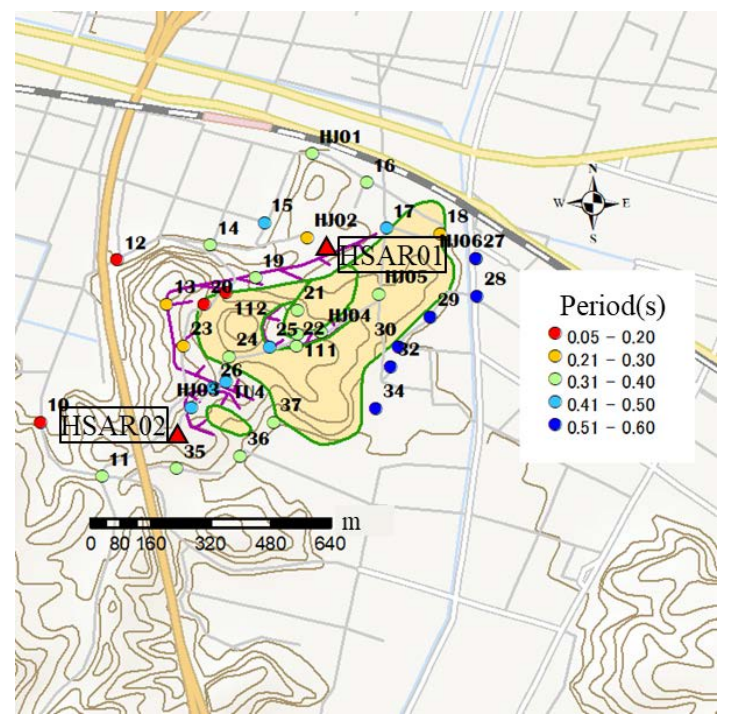

(a) Hojoshima area

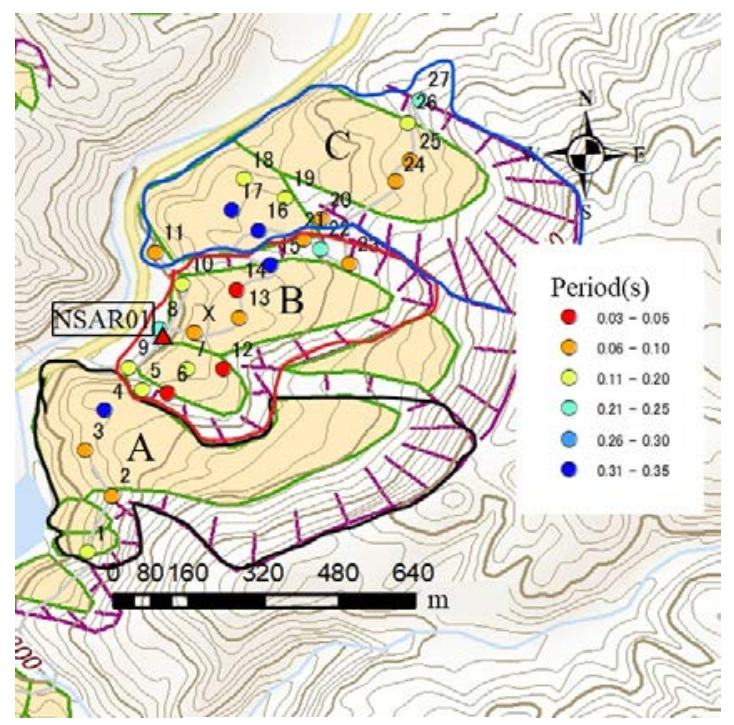

(b) Nawashiro area

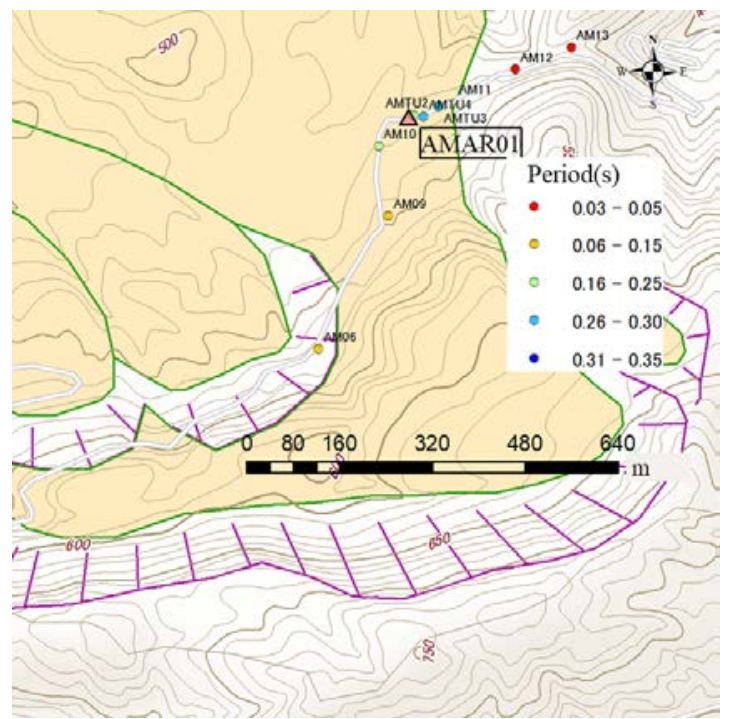

(c) Amadaki area

Fig. 3 Distribution of predominant period
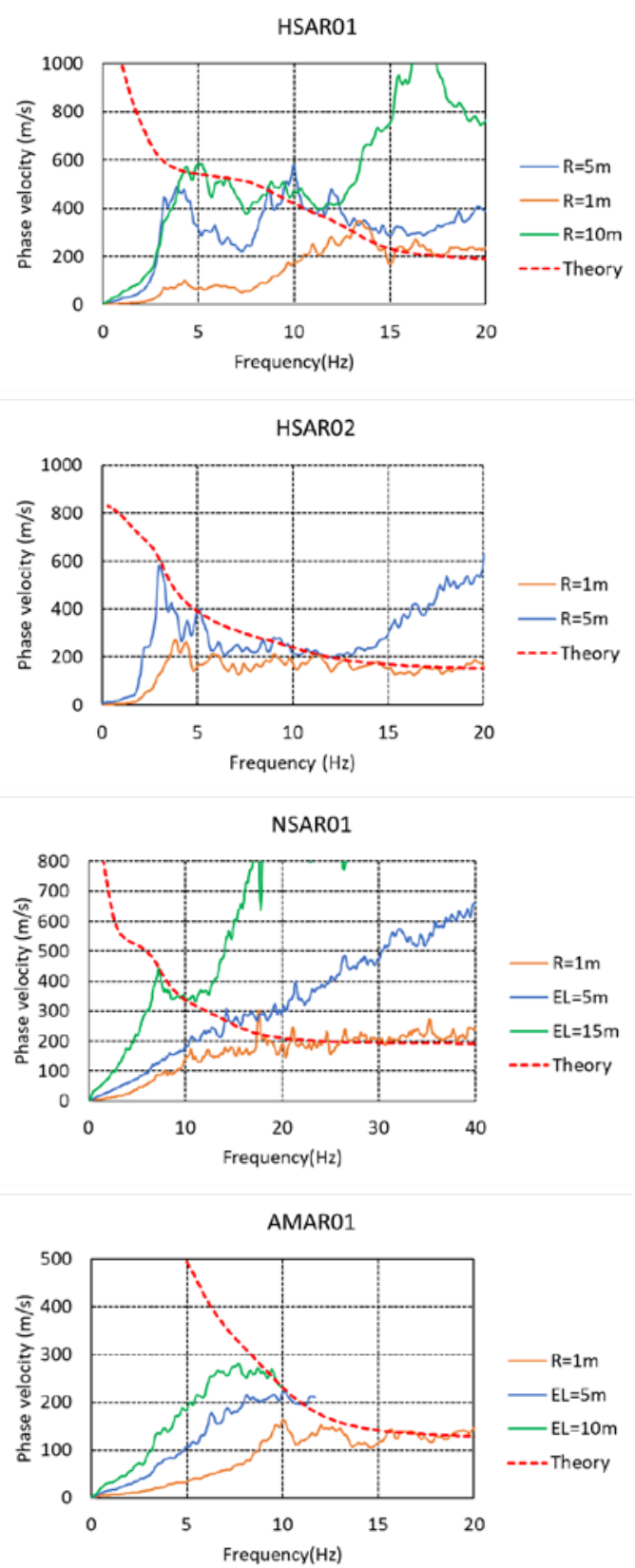

Fig. 4 Dispersion curves of phase velocity

lines are the theoretical values of the Rayleigh waves using the subsurface structural model). The distribution of the predominant H/V spectral periods for each region area is shown in Figure 3.

The phase velocity dispersion curves were estimated from the array observation data using the CCA method [8] in the open analysis tool [7]. The conditions for the analysis are as follows: at least five sections were selected through an automatic extraction using the RMS value of the microtremor record of each seismograph with a segment length of $10.24 \mathrm{~s}$. The power spectrum of these sections was smoothed using a Parzen 
Table 1 Subsurface structural models

\begin{tabular}{|c|c|c|c|}
\hline $\begin{array}{c}\text { Thickness } \\
(\mathrm{m})\end{array}$ & $\begin{array}{c}\rho \\
\left(\mathrm{g} / \mathrm{cm}^{3}\right)\end{array}$ & $\begin{array}{c}\mathrm{Vp} \\
(\mathrm{m} / \mathrm{s})\end{array}$ & $\begin{array}{c}\text { Vs } \\
(\mathrm{m} / \mathrm{s})\end{array}$ \\
\hline 1.5 & 1.7 & 1420 & 120 \\
\hline 6 & 1.9 & 1500 & 200 \\
\hline 100 & 2.0 & 1950 & 600 \\
\hline 200 & 2.1 & 2300 & 900 \\
\hline$\infty$ & 2.2 & 2600 & 1200 \\
\hline
\end{tabular}

\begin{tabular}{|c|c|c|c|}
\hline $\begin{array}{c}\text { Thickness } \\
(\mathrm{m})\end{array}$ & $\begin{array}{c}\rho \\
\left(\mathrm{g} / \mathrm{cm}^{3}\right)\end{array}$ & $\begin{array}{c}\mathrm{Vp} \\
(\mathrm{m} / \mathrm{s})\end{array}$ & $\begin{array}{c}\text { Vs } \\
(\mathrm{m} / \mathrm{s})\end{array}$ \\
\hline 6 & 1.7 & 1460 & 200 \\
\hline 15 & 1.8 & 1560 & 350 \\
\hline 100 & 1.9 & 1970 & 600 \\
\hline 250 & 2.1 & 2300 & 900 \\
\hline$\infty$ & 2.2 & 2620 & 1200 \\
\hline
\end{tabular}

\begin{tabular}{|c|c|c|c|}
\hline $\begin{array}{c}\text { Thickness } \\
(\mathrm{m})\end{array}$ & $\begin{array}{c}\rho \\
\left(\mathrm{g} / \mathrm{cm}^{3}\right)\end{array}$ & $\begin{array}{c}\mathrm{Vp} \\
(\mathrm{m} / \mathrm{s})\end{array}$ & $\begin{array}{c}\mathrm{Vs} \\
(\mathrm{m} / \mathrm{s})\end{array}$ \\
\hline 3 & 1.6 & 1450 & 145 \\
\hline 4 & 1.7 & 1480 & 170 \\
\hline 13 & 1.8 & 1620 & 300 \\
\hline 15 & 1.9 & 1730 & 400 \\
\hline 35 & 2.0 & 1840 & 500 \\
\hline 150 & 2.1 & 2170 & 800 \\
\hline$\infty$ & 2.2 & 2280 & 900 \\
\hline \multicolumn{4}{|c}{} \\
\hline
\end{tabular}

\begin{tabular}{|c|c|c|c|}
\hline $\begin{array}{c}\text { Thickness } \\
(\mathrm{m})\end{array}$ & $\begin{array}{c}\rho \\
\left(\mathrm{g} / \mathrm{cm}^{3}\right)\end{array}$ & $\begin{array}{c}\mathrm{Vp} \\
(\mathrm{m} / \mathrm{s})\end{array}$ & $\begin{array}{c}\text { Vs } \\
(\mathrm{m} / \mathrm{s})\end{array}$ \\
\hline 5 & 1.6 & 1460 & 130 \\
\hline 8 & 1.7 & 1570 & 250 \\
\hline 100 & 1.9 & 1970 & 600 \\
\hline 250 & 2.1 & 2300 & 900 \\
\hline$\infty$ & 2.2 & 2620 & 1200 \\
\hline
\end{tabular}

Table 2 Average S-wave velocity

\begin{tabular}{|c|c|}
\hline & S-wave velocity (m/s) \\
\hline HSAR01 & 184 \\
\hline HSAR02 & 315 \\
\hline NSAR01 & 307 \\
\hline AMAR01 & 204 \\
\hline
\end{tabular}

window with a bandwidth of $0.3 \mathrm{~Hz}$ and then averaged. Using the power spectrum of each seismograph, a phase velocity dispersion curve was obtained based on the CCA method [8]. The dispersion curves of the phase velocity for each site are shown in Figure. 4 (solid lines are curves obtained for each radius, while red dashed lines represent the theoretical values of the Rayleigh waves using the subsurface structural model. We determined the subsurface structures to satisfy the $\mathrm{H} / \mathrm{V}$ spectra and the dispersion curves of the phase velocity by using the fundamental mode of Rayleigh waves within the frequency range of 2-40 $\mathrm{Hz}$. The subsurface structures were determined using forward calculations based on geological situations from borehole data [9]. The parameters of the subsurface structure models are the number of layers, density, P-wave velocity (Vp), S-wave velocity (Vs), and layer thickness. Densities were set based on previous research in Japan [10], and Pwave velocities were set from $\mathrm{S}$-wave velocities [11]. The parameters of the subsurface structure model are listed in Table 1.

The predominant period of the $\mathrm{H} / \mathrm{V}$ spectrum corresponds to the layer thickness of the sedimentary layer of the landslide moving mass, which enabled the average S-wave velocity of the

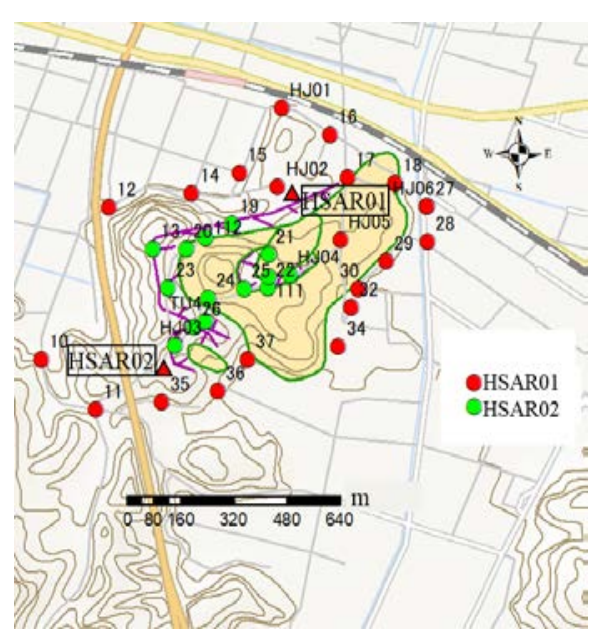

Fig. 5 Location of average S-wave velocity of HSAR01 or HSAR02 at each site in Hojojima

sedimentary layer of the landslide moving mass to be calculated from the obtained subsurface structure model. The average S-wave velocity was calculated using the weighted average of the layer thickness, and the thickness of the layer was estimated from the average $S$-wave velocity and the predominant period based on the 1/4 wavelength rule. The average S-wave velocity used to calculate the layer thickness in each region is listed in Table 2. For the calculation of Hojoshima, the average S-wave velocity of either HSAR01 or HSAR02 was used because the subsurface structure was different depending on the topography, and S-wave velocity is determined by location and topography. Figure 5 shows the model used for each station. The distribution of the thickness of the landslide moving mass for each region is shown in Figure 6.

\section{RESULTS}




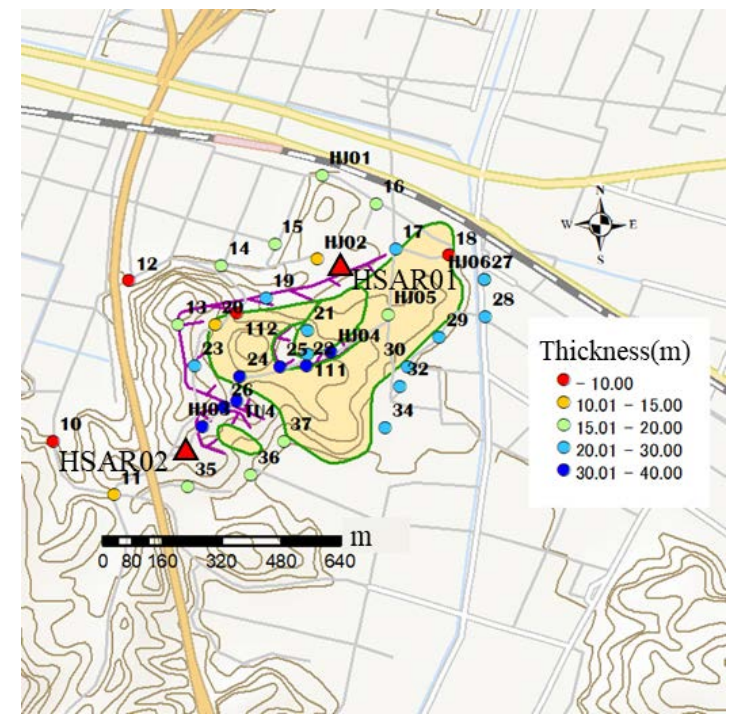

(a) Hojojima area

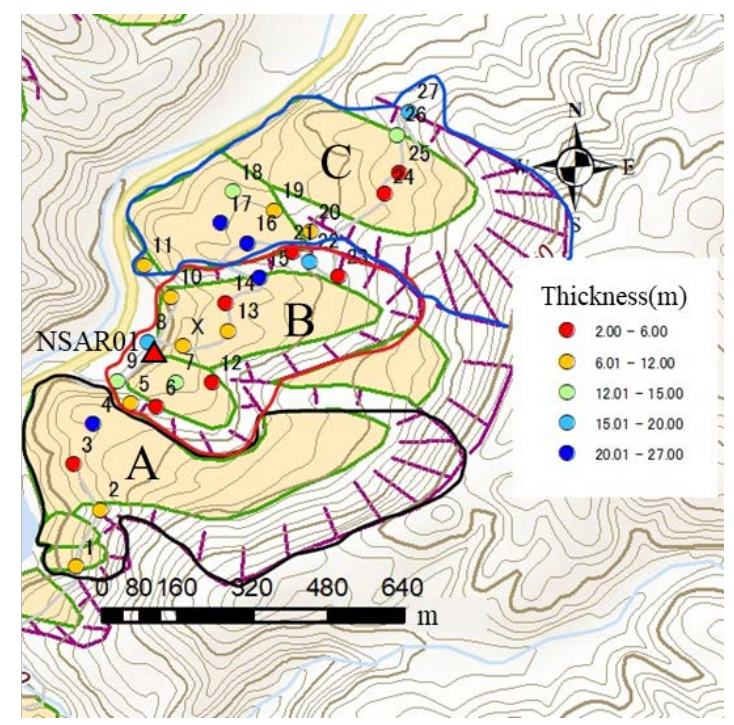

(b) Nawashiro area

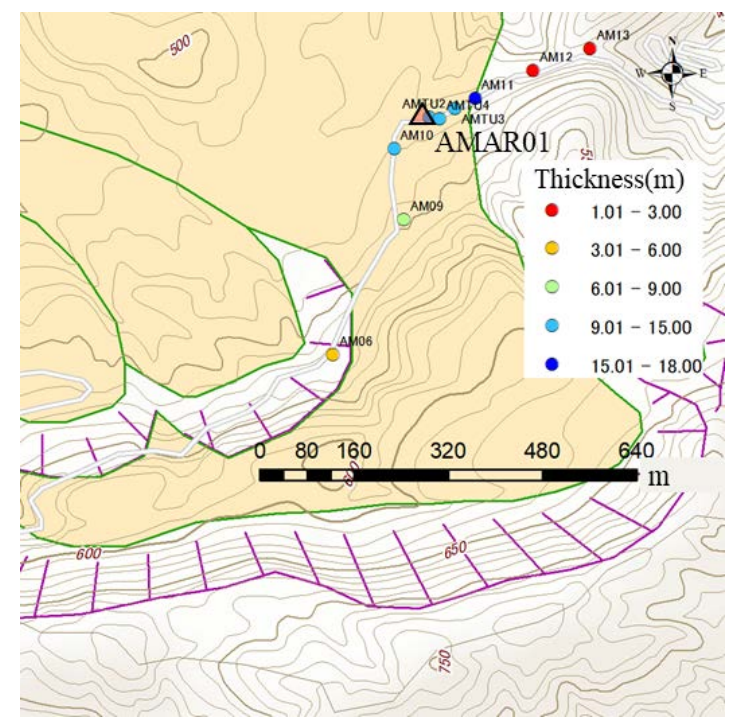

(c) Amadaki area

Fig. 6 Distribution of thickness of sediment layer

\subsection{Distribution of Predominant Periods}

The predominant period distribution in the Hojoshima area (Fig. 3(a)) is about $0.1 \mathrm{~s}$ with a short period for scarp (purple line) and mountainous areas, and about 0.2 - $0.5 \mathrm{~s}$ with a long period for landslide moving mass (yellow-green line, cream-colored areas) and flat areas. The predominant period distribution in the Nawashiro area (Fig. 3(b)), which is topographically divided into three blocks (A, B, and $\mathrm{C}$ ), shows a random distribution of short-and long-period points in the range of $0.1-0.3 \mathrm{~s}$. The distribution trend was independent of the areas of the scarp and landslide moving mass. In the Amedaki area (Fig. 3(c)), the predominant period is about $0.1-0.3 \mathrm{~s}$ for the landslide moving mass. In the scarp area, the predominant period was not found in the $\mathrm{H} / \mathrm{V}$ spectra. The geology of each area is as follows: Hojoshima is dominated by andesite, Nawashiro is dominated by andesite with localized mudstone, and Amedaki is dominated by andesite and tuff conglomerate.

\subsection{Subsurface Structure}

From the subsurface model shown in Table 1, the S-wave velocity structure is as follows: in Hojoshima (HSAR01, HSAR02), the S-wave velocity of the sedimentary layer of the landslide moving mass was quite low $(120 \mathrm{~m} / \mathrm{s}-200 \mathrm{~m} / \mathrm{s})$, and the layer thickness was approximately $7 \mathrm{~m}$. It is considered that the S-wave velocity of a rock layer distributed around HSAR02 gradually changes due to weathering and other effects. In Nawashiro (NASR01), the S-wave velocity of the sedimentary layer of the landslide moving mass is high (200 $\mathrm{m} / \mathrm{s}-350 \mathrm{~m} / \mathrm{s}$ ) and the layer thickness is $21 \mathrm{~m}$, which is thicker than the other two regions. The NASR01 model shows the subsurface structure of block B, and it is considered that the other blocks are similar. In Amedaki (AMAR01), the S-wave velocity of the sedimentary layer of the landslide moving mass was low $(130 \mathrm{~m} / \mathrm{s}-250 \mathrm{~m} / \mathrm{s})$, and the layer thickness was $13 \mathrm{~m}$. The area is an extensive landslide terrain, and the observation point is almost in the middle of the moving mass.

The layer thickness distribution is expressed as follows: in Hojoshima (Fig. 6(a)), the sedimentary layers thickened from the southwestern scarp to the northwestern landslide moving mass, with a maximum thickness of approximately $30 \mathrm{~m}$. In Nawashiro (Fig. 6(b)), the sedimentary layer tends to be thicker in the center of the moving mass at lower elevations and thinner closer to the scarp, and the thickness of the layer exceeds $20 \mathrm{~m}$ at some points. In Amedaki (Fig. 6(c)), the sedimentary layer tends to become thicker from the west to the 
east, with a maximum thickness of approximately $15 \mathrm{~m}$.

\section{CONCLUSION}

Based on the landslide topography distribution map, microtremor surveys were conducted in three areas in Tottori Prefecture, which were determined to be landslide terrain. As a result, we were able to obtain the distribution of the microtremor predominant periods, the subsurface structure model, and the distribution of the layer thickness of the landslide moving mass in each area. The results are as follows:

1) In each region, the predominant period of the $\mathrm{H} / \mathrm{V}$ spectra ranged from $0.1 \mathrm{~s}$ to $0.35 \mathrm{~s}$.

2) It was found that the shape of the H/V spectrum varied locally, with multiple peaks identified, depending on the landslide topography classification and geology.

3) From the subsurface structure of each area based on the array observation, the S-wave velocity of the surface layer of the landslide moving mass was estimated to be $120 \mathrm{~m} / \mathrm{s}$ to $400 \mathrm{~m} / \mathrm{s}$, and the thickness of the layer was $35 \mathrm{~m}$ in Hojoshima, $21 \mathrm{~m}$ in Nawashiro, and 13m in Amedaki.

4) Based on the estimated velocity model and the predominant period of the $\mathrm{H} / \mathrm{V}$ spectrum, the thickness of the surface layer was calculated using the quarter-wavelength law, and the distribution map was created. As a result, the thickness of the surface layer tended to increase in the center of the landslide moving mass.

\section{ACKNOWLEDGMENTS}

Part of this research is based on the results of the graduation thesis by Mr. Atsushi Shimada, who belonged to the Faculty of Engineering, Tottori University. This work was supported by JSPS Grant-in-Aid for Scientific Research JP20K05028 (Principal Investigator: Tatsuya Noguchi).

\section{REFERENCES}

[1] Faris F. and Fawu W., Investigation of the initiation mechanism of an earthquake- induced landslide during rainfall: a case study of the Tandikat landslide, West Sumatra, Indonesia, Geoenvironmental Disasters 2014 1:4., doi:10.1186/s40677-014-0004-3, 2014.

[2] Osanai. N, Yamada T., Hayashi S., Kastura S., Furuichi T., Yanai S., Murakami Y., Miyazaki T., Tanioka Y., Takiguchi S., Miyazaki M., Characteristics of landslides caused by the 2018 Hokkaido Eastern Iburi Earthquake, Landslides,
DOI:10.1007/s10346-019-01206-7, 2019.

[3] National Research Institute for Earth Science and Disaster Prevention, Landslide Maps, Series 21 "The Miyazu and Tottori Region", Explanations of Landslide Distribution Maps, Vol.260, 2005 (in Japanese).

[4] National Research Institute for Earth Science and Disaster Prevention, Landslide Maps, Series 25 “The Matsue and Takahashi Region”, Explanations of Landslide Distribution Maps, Vol.278, 2005 (in Japanese).

[5] Kagawa,T., Noguchi,T., Yoshida,S. and Yamamoto, S., Effect of the surface geology on strong ground motions due to the 2016 Central Tottori Earthquake, Japan, Earth Planets and Space, Vol69, DOI10.1186/s40623-017-0689-0, 2017.

[6] Konno K. and Ohmachi T., A smoothing function sutable for estimation of amplification factor of the surface ground from microtremor and its application, Journal of JSCE, No.524/133, 1995, pp.247-259 (in Japanese with English abstract).

[7] Cho I., Tada T. and Shinozaki Y., Possibility of microtremor array opened up by general theory: Release of analysis tool BIDO, Seismological Society of Japan Fall Meeting in 2009, 2009 (in Japanese).

[8] Cho I., Tada T. and Shinozaki Y., Centerless circular array method: Inferring phase velocities of Rayleigh waves in broad wavelength ranges using microtremor records, Journal of Geophysical Research, 2006, Vo.111, B09315.

[9] National Research Institute for Earth Science and Disaster Resilience, Geo Station (https://www.geo-stn.bosai.go.jp), [Viewed on June 14, 2021]

[10] Noguchi T., Nishikawa H., Yoshida S. and Kagawa T., Estimation of subsurface structure and characteristics of ground vibration based on microtremor and seismic observation in the central Tottori Prefecture, Japan, Journal of Japan Association for Earthquake Engineering, Vol. 19, Issue 6, 2019, pp. 258-271. (in Japanese with English abstract)

[11] Kitsunezaki C., Goto N., Kobayashi Y., Ikawa, T., Horike M., Saito T., Kurota T., Yamane K., Okuzumi K., Estimation of P- and S- wave velocities in deep soil deposits for evaluating ground vibrations in earthquake, Natural disaster science, 1990, 9-3, 1-17. (in Japanese with English abstract)

Copyright (C) Int. J. of GEOMATE All rights reserved, including making copies unless permission is obtained from the copyright proprietors. 